\title{
pombalina
}

(8)

\section{A classe média à deriva}

Autor(es): Estanque, Elísio

Publicado por: Imprensa da Universidade de Coimbra

URL persistente:

URI:http://hdl.handle.net/10316.2/43540

DOI:

DOI:https://doi.org/10.14195/978-989-26-1343-7_41

Accessed : $\quad$ 26-Apr-2023 16:16:50

A navegação consulta e descarregamento dos títulos inseridos nas Bibliotecas Digitais UC Digitalis, UC Pombalina e UC Impactum, pressupõem a aceitação plena e sem reservas dos Termos e Condições de Uso destas Bibliotecas Digitais, disponíveis em https://digitalis.uc.pt/pt-pt/termos.

Conforme exposto nos referidos Termos e Condições de Uso, o descarregamento de títulos de acesso restrito requer uma licença válida de autorização devendo o utilizador aceder ao(s) documento(s) a partir de um endereço de IP da instituição detentora da supramencionada licença.

Ao utilizador é apenas permitido o descarregamento para uso pessoal, pelo que o emprego do(s) título(s) descarregado(s) para outro fim, designadamente comercial, carece de autorização do respetivo autor ou editor da obra.

Na medida em que todas as obras da UC Digitalis se encontram protegidas pelo Código do Direito de Autor e Direitos Conexos e demais legislação aplicável, toda a cópia, parcial ou total, deste documento, nos casos em que é legalmente admitida, deverá conter ou fazer-se acompanhar por este aviso. 


\section{FERNANDA CRAVIDÃO}

\section{IÚCIO CUNHA}

PAULA SANTANA

\section{NORBERTOSANTOS}

(ORG.)

\section{ESPAÇOS E TEMPOS EM GEOGRAFIA}

HOMENAGEM A ANTÓNIO GAMA

IMPRENISA DÁ UNIVERSIDADE DE COIMBRA COIMBRA UNIVERSITY PRESS

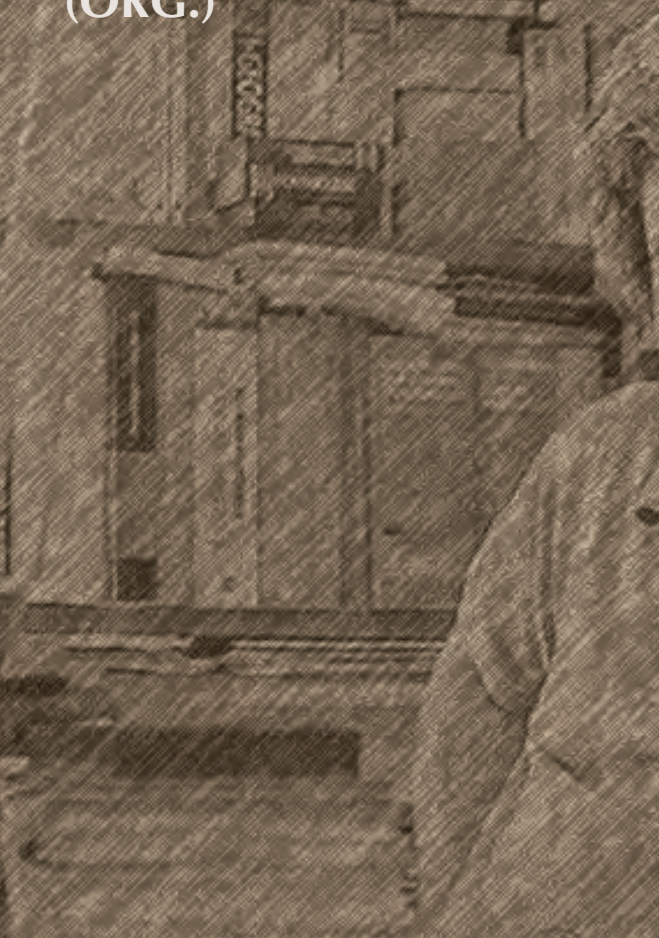




\title{
A ClAsSE MÉdia À DERIVA ${ }^{I}$
}

\author{
Elísio Estanque/elisio.estanque@gmail.com \\ Centro de Estudos Sociais \\ e Faculdade de Economia \\ da Universidade de Coimbra
}

\section{Introdução}

A problemática do espaço - tão cara a António Gama Mendes - é uma das vertentes que nenhum estudo sobre estruturas e práticas sociais pode ignorar. Seja o espaço físico e o território, inevitavelmente associado à posição, estatuto e recursos que os atores sociais mobilizam, seja o próprio critério de proximidade-distância com que os grupos sociais desenham afinidades e demarcaçóes, as variáveis sociológicas inscrevem-se sempre na geografia. No caso especifico da estratificação e das classes, o critério espacial é particularmente importante na medida em que é no espaço que são estruturados os estilos de vida e os habitus que conferem aos diferentes segmentos sociais o seu significado sociológico. O rural e o urbano, o palco e os bastidores, o público e o privado são elementos sobre os quais se reconfiguram as divisôes sociais. A própria "classe média”, no sentido moderno do termo, é inseparável dos processos de demarcação territorial e o nosso país, uma sociedade de recente urbanização, é um bom laboratório

\footnotetext{
1 O presente texto contém uma parte da "Lição" inserida nas Provas de Agregaçâo apresentadas pelo autor na Universidade de Coimbra, em março de 2016.
} 
onde as novas linhas de desigualdade, os estilos de vida e as marcas de distinçấo classistas evidenciam a centralidade desta dimensão. $\mathrm{O}$ trabalho e o lazer, a produçáo e o consumo, a economia e o poder, o conflito e as identidades sáo oposiçóes que - em particular numa sociedade em rápida transformação, como a portuguesa - se projetam com particular acuidade na estruturação espacial, aspetos estes que nos obrigam a salientar a importância da interdisciplinaridade nas ciências sociais, um princípio que o colega aqui homenageado prosseguiu de forma coerente ao longo da sua carreira (Gama, 2008).

Os estudos que tenho vindo a desenvolver em torno da "classe média» destinam-se a mostrar a atualidade do conceito e ao mesmo tempo a analisar as particularidades do fenómeno no caso específico da sociedade portuguesa. Como se sabe, as teorias clássicas da estratificação e das classes sociais constituem os parâmetros que estabeleceram as premissas iniciais desta discussão sociológica. Porém, o contributo que aqui procuro expor parte do princípio de que quer a "análise de classes" vinculada ao marxismo, quer as teorias weberianas da "estratificação social" - sem prejuízo das inspiradoras análises teóricas que ambas nos legaram - requerem um novo esforço de atualização com vista a compreender uma questáo que assume, hoje, contornos cada vez mais complexos.

Com efeito, a sociologia contemporânea assumiu ao longo do século $\mathrm{xx}$, em especial a partir da década de 1960, um papel central na reflexão sobre as classes e a transformação estrutural das sociedades industrializadas do mundo ocidental. Nesse contexto, o conceito de "classe média" revelou-se um dos mais polémicos das ciências sociais, tendo diversos autores do campo marxista questionado mesmo a sua utilidade teórica. Apesar disso, a noção instalou-se de há muito na linguagem corrente e nos meios académicos, pelo que - ainda que fosse por essa simples razão - ignorá-la deixou de fazer sentido. Por um lado, como diria Pierre Bourdieu, a própria nomeação - a classe no papel - não é indiferente à construção prática de similitudes e demarcaçôes estruturadas pela classe objetiva (Bourdieu, 1989). Por outro lado, passou a época em que a repulsa face a esta categoria era justificada por razóes ideológicas. Mais do que recusar uma visão essencialista sobre o conceito, ou seja, mais do que a substância ou "a coisa em si” importa considerar a classe média como problemática. 
De facto, dada a enorme heterogeneidade, a reflexão que ela permite suscitar requer uma atençấo aos efeitos discursivos e sociopolíticos da sua invocaçấo. Nesse sentido podemos começar por perguntar: a) até que ponto a classe média, tal como ela se revelou no mundo ocidental, pode ser concebida como um ator fundamental da mudança social?; b) será essa mudança primordialmente de natureza evolutiva e reformista ou antes tende em certas condiçôes a assumir contornos de radicalismo e de ação coletiva?

\section{Classe média: o nome e a coisa}

A consistência sociológica da noção de "classe média" foi repetidamente questionada ao longo do século passado. Se quisermos reportar-nos a critérios estruturais de inspiração marxista tais como o conceito de relaçôes sociais de produção, dir-se-á que a classe média não possuiu a propriedade dos meios de produçáo (é assalariada) e não controla os grandes recursos de poder ou posiçóes de status monopolizadas pelas elites. Todavia, mais do que ficarmos presos a uma definiçáo conceptual (por mais rigorosa que seja), importa assumir que se trata de um fenómeno que - não sendo novo - requer hoje um novo olhar sociológico, e sobretudo requer novos estudos menos marcados pelo viés ideológico (marxista ou funcionalista). Gorän Therborn, depois de todos os estudos que desenvolveu sobre classes sociais, marxismo e socialismo, propóe-nos hoje uma conceção tão simples como esta: "basicamente, a 'classe média' refere-se aos não-ricos e não-pobres, sem a necessidade de outras características sociais além do consumismo, embora por vezes uma orientaçáo cultural e política esteja incluída" (Therborn, 2013: 178). "Uma classe que não é classe ou um grupo que não é grupo", na formulação de um teórico weberiano (Dahrendorf, 1982), ou seja, sabe-se desde sempre que o termo "classe média" não pode ser entendido como um "ator" dotado de "identidade" ou de "consciência coletiva" no mesmo sentido em que se pensou o operariado. Trata-se, pois, de um agregado de categorias sociais extremamente heterogéneo e instável que não se ajusta a um conceito estrito de "classe". 
Mesmo aceitando que as democracias liberais se baseiam em sistemas económicos concorrenciais, onde a meritocracia favorece a mobilidade social, importa resgatar de Max Weber a importância decisiva das desigualdades de poder (coisa que a escola estrutural-funcionalista se recusou a fazer) e de status para abrir caminho a novas linhas de análise sobre o papel da classe média desde meados do século passado. É, pois, tendo presente esta dimensão que poderemos considerar as seguintes funções atribuídas à "classe média": uma função de almofada, porque quanto mais volumosa for a classe média menor é a propensão para o conflito estrutural; uma função de referência porque foi ela que tornou credível a possibilidade de mobilidade ascendente e a ideia de meritocracia; e uma função de mudança social porque a classe média deu sentido ao projeto progressista $\mathrm{e}$ reformista apropriado pela social-democracia europeia.

É sabido, por outro lado, que os marxistas não atribuíram especial atenção à classe média, desprezando completamente o seu significado político. Karl Marx referiu-se aos pequenos agricultores como um conjunto desagregado e sem capacidade para agir enquanto classe. Daí nasceu a jocosa expressão do "saco de batatas" com que brindou a capacidade do campesinato francês promover uma consciência de classe: "existe entre os pequenos camponeses apenas uma ligação local e em que a similitude de seus interesses não cria organização política, nessa exata medida não constituem uma classe” (Marx, 1969: 115). Além disso, as chamadas classes de transição a que se referia na obra A Luta de Classes em França (1848-1850) eram vistas como o principal suporte dos interesses da classe dominante, dispostas a procurar o conforto, tentando abastecer-se no mesmo "balcão" (leia-se, o Estado capitalista) onde a burguesia tratava dos seus negócios. Noutros momentos, porém, considerava-as como fraçóes e segmentos em transição do período manufatureiro para o capitalismo industrial e destinadas a integrar o proletariado. Seja como for, o certo é que foi a luta conduzida pela classe operária e o movimento sindical desde o século xix que decididamente conduziu à consolidaçáo do Estado de direito e abriu caminho às democracias avançadas da Europa. 


\section{Classe e status}

É nessa linha que se inscreve a consolidação do Estado Providência na Europa do pós-guerra. E porque este modelo social se liga diretamente ao fenómeno aqui em discussão, podemos interrogar-nos sobre o significado dessa viragem no que respeita ao crescimento da "nova" classe média (assalariada) e, indiretamente, à questão conexa da "mobilidade social". Estará ela essencialmente associada ao mercantilismo, à competitividade, à iniciativa individual e à "meritocracia", tal como a pequena burguesia industrial em ascensão há duzentos anos atrás? Na verdade, as camadas sociais aqui em análise não se confundem com a classe média proprietária abordada pelo autor de "Da Democracia na América", isto é, aqueles que se encontram "tão afastados da opulência como da miséria (...), [mas] estando ainda muito próximos da pobreza, vêm de perto os seus rigores, pelo que atribuem aos seus bens um preço imenso (...) e a ideia de ceder a menor partes dele é-lhes insuportável e consideram a sua perda como a última das infelicidades" (Tocqueville, 1988: 272). Apesar de o olhar de Tocqueville sobre os EUA do século xIX ter colocado a ênfase nessa perspetiva, no caso do "velho continente" importa atentar noutro tipo de variáveis.

No contexto europeu do século xx foram, acima de tudo, o programa social-democrata, o crescimento económico, a inovação técnica e a presença dos modernos mecanismos de "diálogo" e concertação - naturalmente acompanhados de inúmeras lutas e ações grevistas - que mais estimularam as novas profissóes e o sentido "neocorporativista" da nova classe média. O papel do Estado e o "compromisso de classe" entre capital e trabalho foram, sem dúvida, decisivos na reconfiguração da classe trabalhadora e de toda a "pirâmide estratificacional" a partir do pós-guerra, mas um tal compromisso beneficiou ainda de outras condicionantes da conjuntura internacional, nomeadamente a influência da "guerra-fria", que favoreceram a estabilidade e o modelo fordista, abrindo caminho a estilos de vida "prósperos" e modelos de consumo marcados pelo individualismo e a aceitação do status quo "burguês" (Burawoy, 2010; Standing, 2014). 
Alguns estudos interessantes sobre mobilidade social durante os "trinta anos dourados" revelaram que um dos efeitos perversos dos fluxos de subida-descida nas atitudes políticas era o facto de os que subiram adotarem regra geral as orientaçóes dos grupos de chegada, enquanto os que desciam tendiam a encarar esse declínio como transitório e a atribuir a si próprios - e não tanto ao sistema económico capitalista - as responsabilidades pela descida, reinvestindo logo a seguir nos seus descendentes o acesso a capitais educacionais e expectativas que lhes facilitou a recuperação do status perdido pela geração anterior. Isto pode ajudar a perceber melhor o declínio do sindicalismo operário. Enquanto o operariado se afirmou como "vanguarda", as franjas da classe média em luta pela "usurpação" (Parkin, 1968 e 1979) deixaram-se guiar por projetos progressistas, mas a implosão dos blue collars e a burocratização do sindicalismo culminou, no Maio de 68, numa nova rutura entre a nova crítica estética (do movimento estudantil) e a velha crítica social (do movimento sindical), o que terá afetado significativamente o avanço dos movimentos emancipatórios (Boltanski e Chiapello, 2009).

À medida que a ação coletiva do operariado e a velha luta de classes se foram esbatendo, boa parte dos descendentes dos blue collars foi engrossando essas novas categorias profissionais, "acomodando-se" à ordem capitalista. Em parte como resultado da iniciativa individual e da "meritocracia", mas sobretudo devido a impacto da mudança estrutural dinamizada pela economia e a ação do Estado, tais mudanças tornaram-se as principais alavancas da mobilidade social e do crescimento da classe média assalariada. Mas, apesar de estigmatizadas pelo discurso marxista da época, por serem expressão dos "vícios burgueses" da sociedade de consumo, estas camadas - em especial os filhos do baby boom do pós-guerra - foram as que mais se filiaram nos sindicatos, as que mais integraram os novos movimentos sociais e as que mais conferiram solidez e coesão social às democracias ocidentais. Recorde-se, de resto, que o próprio movimento operário do século XIx já havia sido liderado pelos trabalhadores mais qualificados (e bem pagos), portanto, pelos pais da futura classe média (Giddens, 1975; Touraine, et al., 1984; Lockwood, 1989; Regini, 1994). 
É inegável que os novos setores assalariados da dita "classe média" - que foram crescendo à custa de um Estado social em expansão, do aumento da modernizaçáo técnica e da burocracia das empresas - forneceram uma base social extraordinariamente importante para a reprodução do capitalismo. Porém, enquanto as teorias da reprodução, sob influência marxista (Bertaux, Bourdieu), realçavam sobretudo o carácter estrutural e a capacidade de cooptação da ordem capitalista dominante, a escola britânica neoweberiana (Goldthorpe, Erikson, Marshal, Parkin, Devine, Savage, etc.) mostrava, com base numa vasta pesquisa empírica, que a recomposiçâo das classes sociais na segunda metade do século xx resultou simultaneamente dos fluxos de mobilidade social e do conflito social; ou seja, da luta de classes conduzida pela "classe média". Recorde-se a conhecida formulaçáo do primeiro destes autores: "mesmo aqueles poucos que chegam ao topo pelo seu mérito passam a querer tudo o resto, não apenas poder e dinheiro, mas também a oportunidade de decidir quem entra e quem fica de fora" (Dahrendorf, 2005).

A mobilidade social e a mudança estrutural do sistema revestiam-se assim de um significado sociológico mais consistente nestas abordagens na medida em que elas não descuraram a crítica à lógica discricionária e às assimetrias de poder e de status, demarcando-se, portanto, do discurso laudatório do marketing do consumo e da meritocracia. Insere-se aí a conhecida formulação de Erikson e Goldhorpe (1992) referente à "classe de serviço", ou seja, a ideia de que, mais do que recompensas pelo talento e mérito, o reconhecimento e condiçôes materiais de que beneficiam estas categorias de classe média devem-se principalmente ao "serviço" que prestam às elites na sua função de zona-tampão. Dito de outra maneira, esses "movimentos de curto alcance" - para cima e para baixo - contribuem para atenuar a conflitualidade porque conferem credibilidade à retórica da meritocracia e da "igualdade de oportunidades" (Savage, et al., 2013). Mas ao lado disso importa realçar, por outro lado, o papel dos novos estratos socioprofissionais cuja visibilidade e protagonismo náo ocorreu apenas em períodos de relativa estabilidade económica e paz social, mas também - e em particular os segmentos juvenis e estudantis - através do seu envolvimento direto em contextos de conflitualidade e luta coletiva, alguns 
deles de grande impacto nos processos de mudança social como, por exemplo, os fortes movimentos sociais dos sixties, aliás, associados a um radicalismo de classe média (Parkin, 1968).

\section{O contexto português}

Como é sabido, a sociedade portuguesa sofreu ao longo dos séculos da incapacidade das suas elites promoverem uma efetiva industrialização e modernizaçáo do país. No século passado, o regime conservador do Estado Novo travou o mais que pôde a abertura económica e prolongou a situação de atraso até ao 25 de Abril de 1974. Só com a democracia e a integração europeia se desenvolveram programas sociais e políticas progressistas que abriram espaço às classes médias assalariadas, na sua maioria inseridas nos meios urbanos e no litoral do país e estruturando modos de vida consentâneos com essa condiçáo. Os impactos mais gerais de um tal processo sobre a economia e a sociedade só muito tardiamente se tornaram visíveis. Pode, portanto, dizer-se que, no caso português a classe média assalariada surgiu tarde e em larga medida à sombra do Estado providência, ele próprio, igualmente frágil e tardio. Esse anacronismo acabou por se revelar decisivo à medida que a situação de crise e o endividamento do país começaram a revelar as fragilidades estruturais com que continuamos a debater-nos. E foi então que se tornou evidente a confusão entre a "ficçáo" e a "realidade" da classe média portuguesa, confusáo que, afinal, comprova uma velha premissa das ciências sociais, desde Max Weber: a ideia de que o social, enquanto construção intersubjetiva do pensamento dos outros, é um misto de ilusão e realidade.

Por outro lado, convém lembrar que no plano objetivo, a classe média, a sua maior ou menor solidez está intimamente associada às oscilaçôes da linha de pobreza. Assim, se considerarmos o critério oficial que define esse limiar a partir de um rendimento equivalente a 60 por cento do salário médio conclui-se que a percentagem dos portugueses em risco de pobreza - que tinha evoluído positivamente na primeira década deste século - voltou a 
intensificar-se nos últimos anos, situando-se nos $18 \%$ em 2009 e nos 19,5\% em 2013, e um relatório mais recente do INE (de 30/01/2015) apontava para um valor de 27,5 por cento, em finais de 2014 . Assim, os portugueses em risco de pobreza corresponderiam a cerca de 2 milhóes e 800 mil. Em termos meramente económicos e segundo o critério proposto por Ursula Dallinger (2011) a situação de classe média enquadra-se no intervalo entre 75\%-150\% do rendimento mediano. Com base nesse indicador, teríamos nesse segmento de rendimento 51,4 por cento dos portugueses. Porém, os critérios podem variar e produzir resultados muito díspares quanto à dimensão da classe média e à sua natureza.

Recorrendo à tipologia de classes usada pelas equipas do ISCTE-IUL na definição das classes, podemos desde logo observar o crescimento (entre 1988-2008) de categorias como os "profissionais técnicos e de enquadramento" (PTE) e os "empregados executantes" (EE), que constituem o grosso dos segmentos inseridos na "classe média". Só estas duas categorias somavam, em 2011, 54,9\% do conjunto da populaçáo ativa. Por sua vez, outros critérios mais restritos - como os que consideram apenas as categorias de "quadros superiores e dirigentes" e os "profissionais técnicos e científicos" como integrando esta categoria - situam a classe média em cerca de $35 \%$ da população portuguesa e mostram uma relativa estabilidade desde a década de 1990 (Mateus, 2013: 332-335). São conhecidos alguns dos problemas mais recentes que atingem diretamente a classe média portuguesa: para além do aumento da pobreza, o sobre-endividamento das famílias, o fenómeno da "pobreza envergonhada", a persistência e agravamento das desigualdades, o bloqueio das carreiras profissionais, os cortes salariais e pensóes de reforma, a generalização do trabalho precário, o disparar do desemprego, etc., etc., são aspetos de uma nova realidade que se foi tornando dramaticamente familiar à classe média (e aos setores mais vulneráveis da população, naturalmente). As medidas de austeridade impostas desde 2011 incidiram com especial violência sobre o funcionalismo e os quadros intermédios - os "quintis" do meio na distribuiçáo do rendimento -, os mesmos que até há pouco serviram de suporte às políticas públicas e programas sociais. $\mathrm{E}$ isso, como não podia deixar de ser, 
está a "proletarizar" amplos setores da classe média, além de lhes impor uma trajetória regressiva e em declínio face ao passado recente (Estanque, 2003 e 2012; Cantante, 2013).

\section{Rebelióes de classe média}

Tratou-se de uma sucessão de rebeliôes que trouxeram à cena novos protagonistas, novas formas de mobilização, repolitizaram numa escala mais ampla o papel do ciberativismo, deram ao segmento do precariado um outro significado (Standing, 2014), no qual as tradicionais demarcaçôes e fronteiras voltaram a ser questionadas (à semelhança dos movimentos sociais dos anos sessenta e setenta do século xx), já que os novos atores destas mobilizaçóes puseram em causa - como argumentei num recente artigo da Revista Critica de Ciências Sociais, Estanque, 2014 - algumas das dicotomias clássicas como o individual/ coletivo, o público/ privado ou a política/ estética. A heterogeneidade, a presença massiva da juventude, a indignação contra a austeridade, as preocupaçóes com a precariedade e o aumento do desemprego, ao lado do carácter espontâneo e inorgânico destas manifestaçôes, são alguns dos seus traços distintivos. Mas estes protestos transportavam já uma pulsão de classe média. Uma classe média que, nomeadamente no caso de Portugal, já sentia as forças do sistema a pressioná-la no sentido descendente. No sentido do empobrecimento, como de resto se viria a comprovar nos anos subsequentes. Estarão as classes médias do mundo ocidental a viver o ressentimento de terem sido abandonadas pelas oligarquias e as elites económicas? Terão tomado consciência da importância vital do Estado social hoje ameaçado?

Os contornos ambivalentes dessas rebelióes e o seu carácter fluído e inorgânico dificultam qualquer diagnóstico quanto aos contornos dos seus reportórios políticos e até mesmo o perfil das suas lideranças (nem sempre identificáveis). Esta enorme diversidade de contextos socioculturais e experiências de ativismo náo deixa de ocorrer num mundo cada vez mais interconectado em que as contaminaçóes transcendem a geografia, tornam-se "virais", circulando e 
metamorfoseando-se em novas formas de hibridismo e estruturas simbólicas cujo significado político carece de novos estudos sociológicos (Castells, 2013). Vale a pena pensar o papel das redes virtuais (Facebook, Twitter, etc.) na sua relação com as espacialidades locais para compreender as novas dinâmicas de estruturação identitária e de mobilização, em especial junto da juventude. Em muitos contextos juvenis, por exemplo, entre os segmentos subalternos, as experiências de sociabilidade são em geral marcadas pela violência e a exclusão - como é o caso da vivência quotidiana nos bairros periféricos das grandes metrópoles -, a que as culturas hip hop da era global tentam dar expressão. Nesses ambientes, a familiaridade dos adolescentes com os novos meios eletrónicos ajudou a potenciar uma relação ambivalente entre o seu mundo físico, relativamente fechado e segregado, e o mundo de ficções subjetivas em que as conexóes por via dos telemóveis, iPhones e Tablets, ajudam a recriar o seu imaginário rebelde ou consumista (ou ambos). Essas comunidades de convívio, meio-físicas meio-virtuais (ou as duas coisas ao mesmo tempo), funcionam como novas teias de significado, substituindo-se ou complementando os velhos laços de sociabilidade primária. Muitos destes grupos de jovens, inseridos na fronteira entre uma classe-média-instalada que os hostitliza e um mundo de paraisos artificiais que constantemente os seduz, onde o "eu" construído e projetado no "outro virtual" se confunde e readapta em cada esquina da ampla comunidade virtual-real. As performances de grupo, os rolezinhos, as mass mobs e outras pequenas encenaçóes rebeldes exprimem bem essas dinâmicas dissonantes. O facebook e outras redes da internet foram os meios de difusão para mais de 80 por cento dos manifestantes nas manifestações de junho de 2013. No calor destes protestos foi possível identificar alguns elementos reveladores de um ethos de classe média, apesar de mal definido ou subliminar. A própria plasticidade e o "décor" com que se mostram diversos sub-grupos de manifestantes é significativa do seu habitus ainda relativamente indefinido na estrutura de classes: para muitos, estar na manifé tão importante como o ato de divulgar a foto no facebook, onde se exibe o disfarce mais apropriado ou o ato "heróico" mais audacioso para enfrentar a ameaça policial, podendo ainda fornecer um fragmento de "glória” na TV (Estanque, 2014). 


\section{Conclusão}

Estamos porventura perante duas faces distintas de uma "classe" que, no plano da luta política e das subjetividades continua a caminhar no limbo. Mas, retomando uma ideia avançada inicialmente, pode postular-se a existência de duas classes médias: uma "classe média" orientada pela usurpação excludente (que persegue os padrôes de vida das elites); e uma "classe média" orientada pelo sentido emancipatório (que pode indignar-se em nome dos pobres e mobilizar-se, por exemplo, na defesa do Estado social, à sombra do qual ganhou esse estatuto).

A presença da juventude foi um dos traços marcantes deste ciclo de rebeliôes, quer na Europa quer na América Latina. Uma juventude escolarizada e muito familiarizada com os novos meios de comunicação por satélite; que, segundo os critérios do rendimento e da escolaridade, pertence aos estratos intermédios da estratificaçáo; ou que se encontra no início de um percurso, talvez no primeiro degrau de uma expectável subida da escada social. Por isso, os seus padrôes de gosto, subjetividades e orientaçôes dirigem-se a um horizonte de classe média. Também neste caso, o contexto urbano e a centralidade das praças ocupadas por milhôes de manifestantes, com a visibilidade que as redes mediáticas imprimem aos núcleos urbanos das principais metrópoles, comprovam o simbolismo estético-expressivo destas mobilizaçóes e o papel estruturante da dimensão espacial. É nestes centros cosmopolitas que as dinâmicas paradoxais, com o caráter policromático dos grandes aglomerados, podem adquirir uma plasticidade vertiginosa no seu poder atrativo. Aí se encontram, convivem e confrontam, de um lado, forças de orientaçáo progressista que se exprimem em grupos politizados, organizados e com propostas radicais, e, de outro lado, lógicas de multidão inorgânica, momentaneamente guiadas por "pulsōes" irracionais ou que se radicalizam apenas por via da excitaçáo de um coletivo magnetizado e inebriado pelo próprio fluxo da "multidáo". 


\section{Referências bibliográficas}

Bourdieu, Pierre (1989). O poder simbólico. Lisboa: Difel.

Burawoy, Michael (2010). O marxismo encontra Bourdieu. Campinas: Editora da Unicamp.

Cantante, Frederico (2013). A magreza das classes médias em Portugal. In Renato M. Carmo (org.), Portugal uma sociedade de classes: polarização social e vulnerabilidade, Lisboa, Ediçōes 70. Ed. Monde Diplomatique, pp. 129-150.

Castells, Manuel (2013). Redes de indignação e de esperança. Rio de Janeiro: Zahar Editores.

Dahrendorf, Ralf (2005). Ascensão e queda da meritocracia. Artigo de opinião no jornal Público, 2/05/2005. P. 7.

Dahrendorf, Ralf (1982). As classes e seus conflitos na sociedade industrial. Brasília: Editora da Universidade de Brasília.

Dallinger, Ursula (2011). The endangered middle class? A comparative analysis of the role public redistribution plays. In Luxembourg income study (LSI). Working Paper, n. ${ }^{\circ} 565$.

Erikson, Robert \& John Goldthorpe (1992). Constant flux: a study of class mobility in industrial societies. Oxford: Clarendon Press.

Estanque, Elísio (2003). O efeito classe média - desigualdades e oportunidades no limiar do século xxi. In M. V. Cabral, J. Vala \& A. Freire (orgs.), Percep̧̧óes e avaliaçōes das desigualdades e da justiça em Portugal numa perspectiva comparada. Lisboa: ICS, pp. 69-105.

Estanque, Elísio (2012). A classe média. Ascensão e declínio. Lisboa: Fundação Francisco Manuel dos Santos.

Estanque, Elísio (2014). Rebeliôes de classe média? Precariedade e movimentos sociais em Portugal (2011-2013). Revista critica de Ciências Sociais, Vol. 103, pp. 53-80.

Gama, António (2008). Fundamentos para uma geografia do tempo livre. In Norberto Santos \& António Gama (orgs.), Lazer. Da libertação do tempo à conquista das práticas. Coimbra: Imprensa da Universidade, pp. 85-106.

Giddens, Anthony (1975). A estrutura de classes nas sociedades avançadas. Rio de Janeiro: Zahar Editores.

Lockwood, David (1989). The blackcoated worker. A studie in class consciousness. Oxford: Oxford University Press/Clarendon.

Marx, Karl (1969). O 18 brumário de Luiz Bonaparte. Rio de Janeiro: Paz e Terra.

Mateus, Augusto (coord.) (2013). 25 anos de Portugal Europeu: a economia, a sociedade e os fundos estruturais. Lisboa: Fundaçáo Francisco Manuel dos Santos.

Parkin, Frank (1968). Middle class radicalism. Manchester: Manchester University Press.

Parkin, Frank (1978). Class inequality and political order. Londres: Granada Publications.

Parkin, Frank (1979). Marxism and class theory. A bourgeois critique. London: Tavistock.

Regini, Marino (ed.) (1994). The future of labour movements. London: Sage.

Savage, Mike et al. (2013). A new model of social class: Findings from the BBC's Great British Class Survey Experiment. Sociology, 0(0), pp. 1-32.

Standing, Guy (2014). O precariado. A nova classe perigosa. Lisboa: Presença.

Therborn, Gorän (2013). The killing fields of inequality. Cambridge: Polity Press. 
Tocqueville, Alexis de (1988). De la democracie en Amérique. In M. Braga da Cruz, Teorias Sociológicas: os fundadores e os clássicos. Vol. I, Lisboa: Fundação Calouste Gulbenkian, pp. 257-295.

Touraine, Alain; Wieviorka, Michel \& Dubet, François (1984). Le mouvement ouvrier. Paris: Fayard. 